\title{
Modified Boundary Condition for Membrane Wall Concentration Prediction in Narrow Membrane Channel
}

\author{
Received in revised form 3 June 2005, accepted 3 June 2005 \\ A. L. Ahmad ${ }^{1 *}$ K. K. Lau ${ }^{2}$, M. Z. Abu Bakar ${ }^{3}$ \& S. R. Abd. Shukor ${ }^{4}$ \\ ${ }^{1,2,3 \& 4}$ School of Chemical Engineering, Engineering Campus, Seri Ampangan, Universiti Sains Malaysia, \\ 14300 Nibong Tebal, Penang, Malaysia
}

\begin{abstract}
The efforts of CFD simulation study to reveal the membrane wall concentration in the membrane channel which consider hydrodynamics and permeation properties are found to be inadequate. Hence, the ultimate objective of this paper is focusing on the employment of modified boundary condition to model the membrane interface in the membrane channel. Permeation properties such as permeation flux and concentration have been integrated in this modified boundary condition. Commercial CFD simulation package has been utilized to predict the membrane wall concentration for different transmembrane pressure and feed Reynolds number in the membrane channel. The simulated results were validated and compared with the published data from literature, showing a satisfactory agreement. This study has proven the increment in feed Reynolds number can enhance the mass transfer rate and suppress the formation membrane wall concentration. The utilization of modified boundary condition has promoted the accuracy and capability of commercial CFD simulation package to model and predict the hydrodynamics and permeation phenomenon in the membrane channel.
\end{abstract}

Keywords : Modified boundary condition, concentration polarization, computational fluid dynamics (CFD) simulation, mass transfer coefficient, hydrodynamics

\subsection{INTRODUCTION}

Studies for the membrane separation mechanisms have been carried out intensively for the past several decades. Understanding of the hydrodynamics behavior for the fluid flowing adjacent to the membrane wall has been enhanced parallel with the development of knowledge in the membrane separation mechanisms. The development of membrane wall concentration due to the hydrodynamics contributes to the occurrence of concentration polarization phenomena which subsequently reduces the permeation flux and solute rejection ability of the membrane. Hence, numerous studies for revealing the hydrodynamics behavior for the fluid flowing adjacent to the membrane wall have been conducted by the Computational Fluids Dynamics (CFD) modeling and simulations.

Special numerical code had been developed for 2 dimensional domain to yield the fluid flow profile and membrane permeation data [1]. Geraldes et al. [2] had applied this technique to reveal

* Correspondence to: A. L. Ahmad (e-mail: chlatif@eng.usm.my, tel: +60 (4) 5937788, fax: +60 (4) 5941013) 
the hydrodynamics and the membrane transport mechanism in the empty membrane channel. Similar technique had also been utilized by Pinho et al. [3] to determine and compared the intrinsic rejection coefficients obtained from experiment and simulations. Modified governing equation in stream function and vorticity had also been utilized to link the membrane transport equation for the computation of fluid flow and membrane transport profile in the empty membrane channel [4]. Besides, membrane channel filled with ladder type spacer had been discretized in 2-D and laminar condition to predict the concentration polarization profile by the employment of this CFD mathematical modeling method [5-7].

Cao et al. [8] had simulated the velocity profile and turbulent kinetic energy distributions in the spacer-filled channel. The study had proven the existence of the spacer is plausible to improve the local shear stress on the membrane surface and produces eddy activities for mass transfer enhancement and fouling reduction. Modifications in boundary condition in CFD simulation can offer significant savings in computational time and costs. Hence, periodic boundary conditions in the stream wise direction had been employed as an alternative to portray the CFD computational domain for spacer filled channel with a single spacer [9].

Commercial CFD simulations codes (CFX) had been employed by Schwinge et al. [10] to simulate the hydrodynamics and mass transfer phenomenon in the spacer filled channel. They had conducted studies on flow patterns and mass transfer enhancement in narrow spacer-filled channels with CFD [11-13]. The flow patterns were examined for a single filament adjacent to the wall and centered in the channel and for three different spacer configurations, the cavity, zigzag and submerged spacer, with variations in mesh length, filament diameter and Reynolds number [11]. Large recirculation regions were formed behind the filaments and the flow around the filament increased the shear stress on the wall. The CFD model was also used to study the effects of Reynolds number, mesh length and filament diameter on mass transfer enhancement for three spacer configurations, a cavity, a zigzag and a submerged spacer [12]. Effort had also been carried out to conduct the simulation of unsteady flow for the spacer filled channel [13-14]. The flow was computed for different filament configurations for channel Reynolds numbers up to 2000. For the filament diameter, channel height and spacer mesh length examined, the transition to unsteady flow for multiple filament spacers occurs above $R e_{\text {ch }}$ of 400 for cavity, submerged and zigzag spacers.

Meanwhile, 3-D laminar CFD simulation had been carried out for the SWM feed channel to evaluate mass transfer coefficients and power consumption for commercial net spacers. Li et al. $[15,16]$ had investigated on the relation between the Sherwood and power numbers using 3-D CFD transient models for low-Reynolds flows in non-woven spacer-filled channel. The study had revealed an optimum ratio for channel height over spacer length to yield maximum mass transfer coefficient with moderate power consumption. Consequent study had also been conducted experimentally to validate the optimum ratio [17].

Inevitably, the improvements in CFD simulation technique and methodology had accelerated the simulations speed and offer the visualization of fluid flow pattern in the complex 3-D spacer-filled domain. However, CFD simulations employing commercial CFD code for fluid flow in the membrane channel developed by researchers mentioned above are found to be restricted to the hydrodynamics condition prediction for the fluid adjacent to the membrane which assume membrane as an impermeable wall with zero concentration build-up (except Geraldes $e t$ al. who developed special numerical code for 2-D laminar domain). This assumption has neglected the mass transport across the membrane and might leads to the incorrect assessment of the concentration polarization phenomenon. To overcome this problem, Wiley et al. $[18,19]$ had conducted 2-D CFD simulation which involved concentration polarization prediction. They had integrated the wall concentration value with the adjacent fluid hydrodynamics to suit the particular CFD simulation with the commercial finite control volume simulator CFX 4 . 
Several researchers have agreed that it is a challenge to integrate the permeation properties in the CFD simulation codes $[10,18,19]$. The availability of CFD simulation study to reveal the concentration polarization profile which consider hydrodynamics and membrane transport mechanisms in the membrane channel is found to be inadequate. The objectives of this paper are aimed to utilize the CFD simulation (commercial CFD package FLUENT v6) to evaluate membrane wall concentration and mass transfer coefficient under different operating pressure and feed Reynolds number in the membrane channel. Permeation conditions such as permeation flux, permeation concentration and membrane wall concentration have been integrated in the modified boundary condition.

\subsection{THEORY}

\subsection{Governing Equations}

The hydrodynamics of the fluid flow condition can be discretized by the solution of the governing equations. The governing Equations (1-4) shown below were used to solve steady state laminar fluid flow for 2-dimensional membrane channel domain with the consideration of solute concentration variation. The detailed solutions of these equations are shown in section 2.2 .

Continuity equation:

$$
\frac{\partial(\rho u)}{\partial x}+\frac{\partial(\rho v)}{\partial y}=0
$$

Navier-Stokes Equation in $\mathrm{x}$-direction:

$$
u \frac{\partial(\rho u)}{\partial x}+v \frac{\partial(\rho u)}{\partial y}=-\frac{\partial P}{\partial x}+\frac{\partial}{\partial x}\left(\mu \frac{\partial u}{\partial x}\right)+\frac{\partial}{\partial y}\left(\mu \frac{\partial u}{\partial y}\right)
$$

Navier-Stokes Equation in y-direction:

$$
u \frac{\partial(\rho v)}{\partial x}+v \frac{\partial(\rho v)}{\partial y}=-\frac{\partial P}{\partial y}+\frac{\partial}{\partial x}\left(\mu \frac{\partial v}{\partial x}\right)+\frac{\partial}{\partial y}\left(\mu \frac{\partial u}{\partial y}\right)
$$

Solute Conservation Equation:

$$
\frac{\partial\left(\rho u m_{A}\right)}{\partial x}+\frac{\partial\left(\rho v m_{A}\right)}{\partial y}=\frac{\partial}{\partial x}\left(\rho D_{A B} \frac{\partial m_{A}}{\partial x}\right)+\frac{\partial}{\partial y}\left(\rho D_{A B} \frac{\partial m_{A}}{\partial y}\right)
$$

The boundary conditions which describe the current simulated computational domain is represented by Equations (5-8). A plug flow velocity inlet was applied in the entrance of the membrane channel. Top part of the channel was assumed to be impermeable wall. Fluid flowing out of the channel was assumed to exist in a fully developed condition where all changes for the flow parameters was equal to zero. No-slip condition where $u=0$ was fixed for the wall and membrane interface. Due to the limitation of the solver, wall boundary condition (refer to Equation (7)) with the incorporation of User Defined Function (UDF) was used to model the membrane wall concentration for the membrane interface (assuming $v=0)$. Permeate flux $\left(J_{v}\right)$ and permeate concentration $\left(\mathrm{C}_{A P}\right)$ are assumed to be constant along the flow channel. The permeate volume flux $\left(J_{v}\right)$ and permeate concentration $\left(\mathrm{C}_{A P}\right)$ values were obtained from published literature [3]. 
Mathematically, these boundary conditions are expressed as follows:

For $x=0$ and $0<y<h$,

$$
u=u_{0} ; \quad v=0 ; \quad C_{A}=C_{A f}
$$

For $x=l$ and $0<y<h$,

$$
\frac{\partial u}{\partial x}=0 ; \quad \frac{\partial v}{\partial x}=0 ; \quad \frac{\partial C_{A}}{\partial x}=0
$$

For $y=0$ and $0<x<l$,

$$
u=0 ; \quad v=0 ; \quad D_{A B} \frac{\partial C_{A}}{\partial y}+J_{v} \times C_{A}=J_{v} \times C_{A p}
$$

For $y=h$ and $0<x<l$,

$$
u=0 ; \quad v=0 ; \quad \frac{\partial C_{A}}{\partial y}=0
$$

\subsection{Simulation Conditions}

The simulated domain was $200 \mathrm{~mm}$ in length and $0.7 \mathrm{~mm}$ in height. In order to eliminate the effect of mesh quality and size on the results, initial simulations were carried out with four mesh resolutions, $50 \times 40,50 \times 50,100 \times 100$, and $200 \times 200$. It was found that when the resolution was increased above $50 \times 50$, it had little effect on the solution in terms of velocity, shear stress and mass fraction. Therefore, the computational grid was constructed with $50 \times 50$ cells. Approximately $75 \%$ of the generated nodes grids were allocated at the near membrane region due to the existence of high concentration profile adjacent to the membrane interface. The computational domain is shown in Figure 1. Due to the laminar conditions in the membrane channel, steady state simulation was used. The convergence criterions for the velocity and temperature parameters were fixed to $0.001 \%$. Higher convergence criterion was set for solute $\mathrm{NaCl}(0.00001 \%)$ to offer sufficient iteration for complete convergence between boundary grid and the interior mesh grid.

Solute (A) - solvent (B) system which consist of sodium chloride ( $\mathrm{NaCl}$ ) and water were defined as the feed material before executing the simulation loops. Three different types of transmembrane pressure $(\Delta P)$ were utilized in this simulation. The permeate volume flux $\left(J_{v}\right)$ and permeate concentration $\left(\mathrm{C}_{A P}\right)$ under these transmembrane pressure were obtained from literature [3]. The length and height of the membrane channel are identical with the dimensions reported in the literature [3]. The details of physical transports properties for $\mathrm{NaCl}$ solution are summarized in Table 1 .

Fluent $v 6$ was used as the commercial CFD simulation package in this work to visualize the flow condition in this narrow membrane channel. Discretization of the governing equations was carried out based on control volume technique. The discrete velocities and pressures were stored by a nonstaggered system which consists of cells and faces. These values were stored in the cells center. Faces values would be evaluated through interpolation using first order upwind scheme. The velocity and pressure parameters would be linked and solved by SIMPLE algorithm and accelerated by algebraic multigrid solver (AMG). The detailed of the simulation procedures are demonstrated in Figure 2. Fluid properties were updated, based on the current solution. If the calculation has just begun, the fluid properties would be updated based on the initialized solution. The Navier-Stokes equations (Equations (2) and (3)) in $\mathrm{x}$ and $\mathrm{y}$ directions were solved in turn using current values for pressure and face mass fluxes, in order to update the velocity field. Since the velocities obtained earlier might 


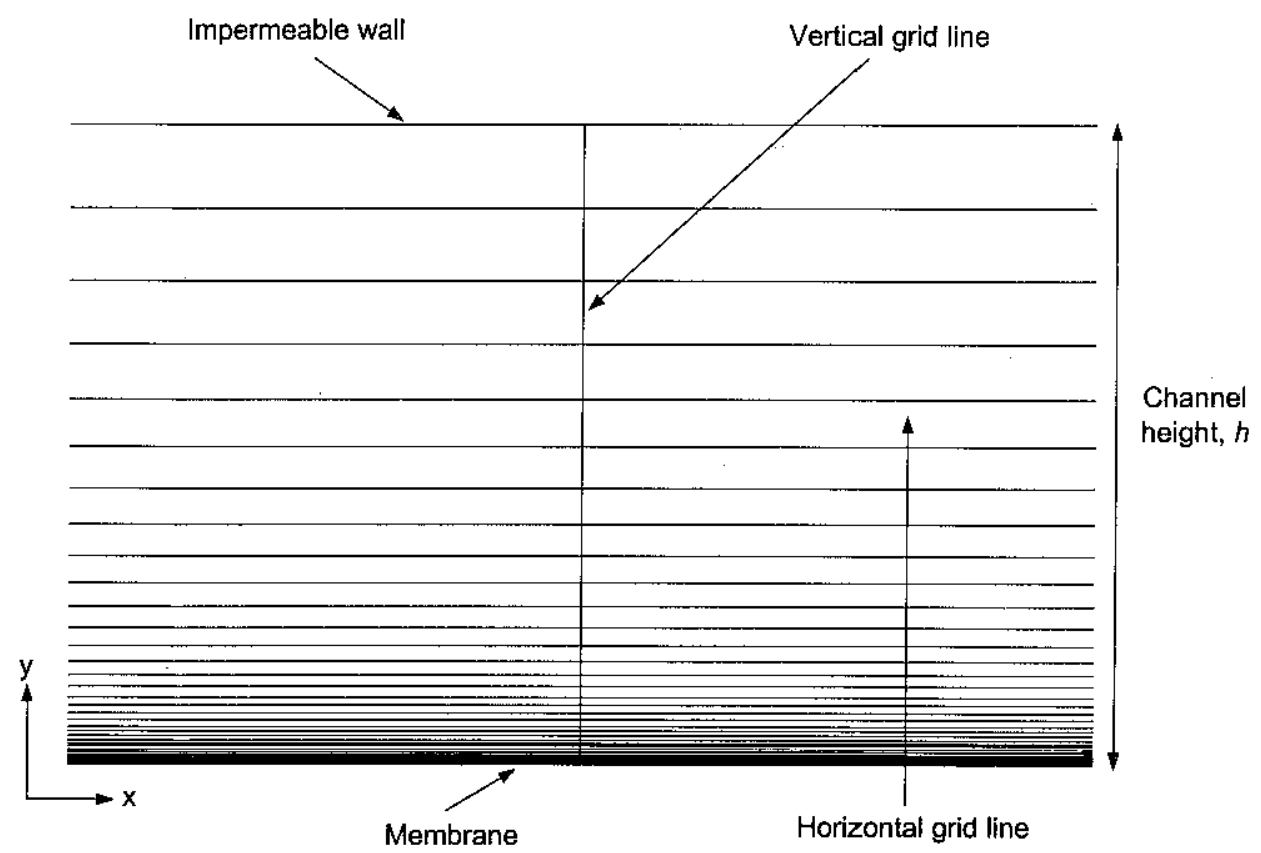

Figure 1. Part of the computational domain for narrow membrane channel

Table 1 Physical Transport Properties for $\mathrm{NaCl}$ solution, $\mathrm{C}_{A f}=0.2 \mathrm{~kg} / \mathrm{m}^{3}$ at $\mathrm{T}=25^{\circ} \mathrm{C}$

\begin{tabular}{ccc}
$\begin{array}{c}\text { Viscosity } \\
\mu \times 10^{4}(\mathbf{P a . s})\end{array}$ & $\begin{array}{c}\text { Binary Diffusion Coefficient } \\
\mathbf{D}_{\mathrm{AB}} \times \mathbf{1 0 ^ { \mathbf { 9 } }}\left(\mathbf{m}^{\mathbf{2}} / \mathbf{s}\right)\end{array}$ & $\begin{array}{c}\text { Density } \\
\boldsymbol{\rho}\left(\mathbf{k g} / \mathbf{m}^{\mathbf{3}}\right)\end{array}$ \\
\hline 9.072 & 2.3070 & 997 \\
\hline
\end{tabular}

a obtained from Perry's Chemical Engineer's Handbook Fifth Edition [20]

${ }^{b}$ calculated value based on Wilke-Chang equation [21]

not satisfy the continuity equation (Equation (1)) locally, SIMPLE algorithm would be used as the pressure correction equation to obtain the necessary corrections to the pressure and velocity fields and the face mass fluxes such that continuity was satisfied. Equation for scalars such as solute conservation (Equation (4)) was solved using the previously updated values of the other variables. A check for convergence of the equation set was made. These steps were continued until the convergence criteria were met.

\subsection{Modified Boundary Condition - User Defined Function (UDF)}

Basically, UDF is written in ' $C$ ' programming language. It can access FLUENT solver data using predefined macros or function supplied by the simulator. The UDF would be interpreted and hooked to the solver during simulation. This UDF would access the solver data, perform calculation on the data and update the solver data repeatedly for every iteration. Under normal simulation without UDF integration, there is only one way to define boundary condition for membrane interface. Typically, 


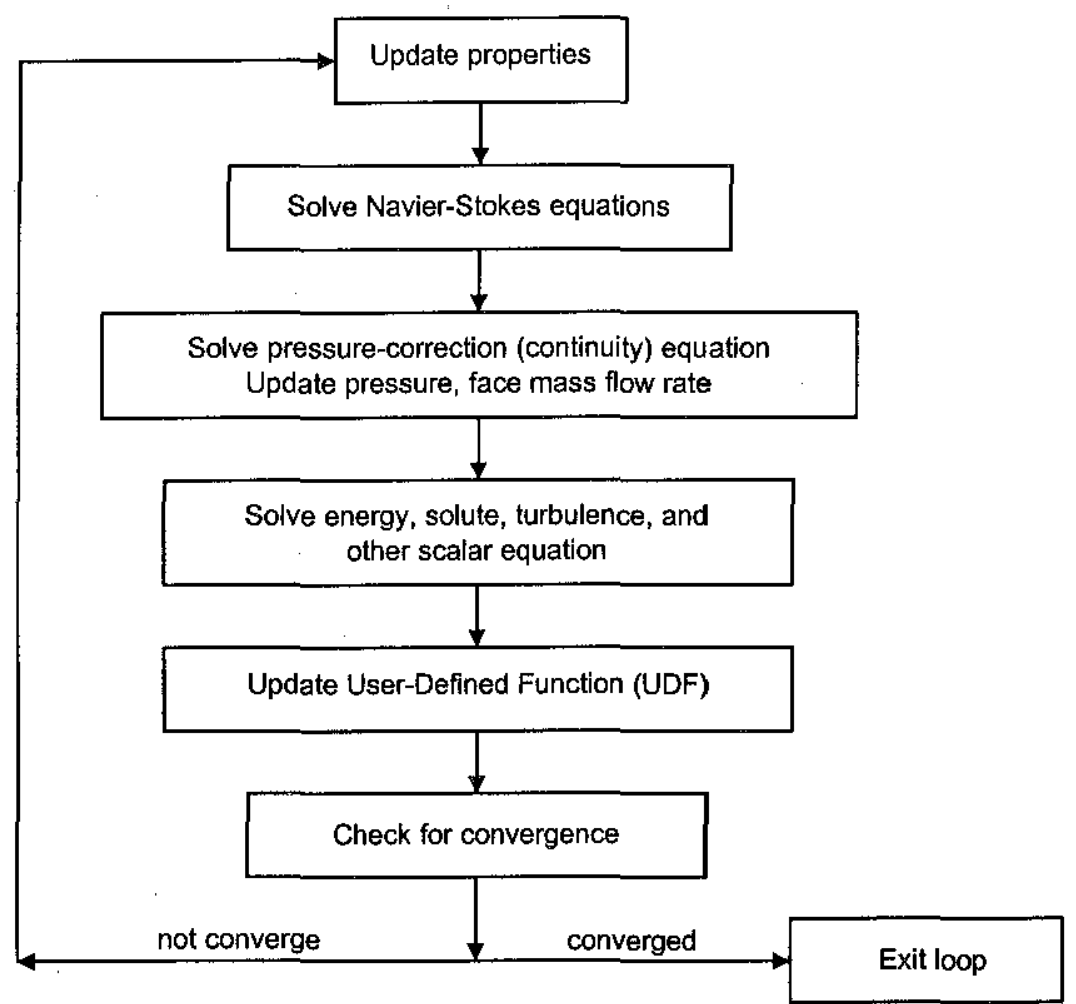

Figure 2 Simulation procedures using segregated solver in FLUENT v6

Dirichlet boundary condition will be used to simulate the concentration profile for this semi-permeable surface. This constant boundary condition value is not suitable to model the membrane interface since the concentration on the membrane interface will vary according to the fluid hydrodynamics and the membrane transport properties.

By integrating UDF file in current simulated domain, boundary condition for the concentration profile in the membrane interface would be more accurately predicted. This is due to the incorporation of Robin boundary condition which describes the film theory for the concentration profile in the membrane boundary condition. 'Define Profile' macro would be utilized parallel with the adjacent cell index to represent the film theory which links the relation between the hydrodynamics and the membrane transport phenomena. Any changes in the fluid flow adjacent to the membrane interface will be computed by the UDF. The specific UDF would update the solver data to simulate the wall concentration. Figure 3 shows the mechanism for solver data accessing by UDF.

\subsection{Simulation Parameters}

Concentration polarization factor, $\Gamma$ will be evaluated from the simulated membrane concentration, $C_{A w}$ according to this relation:

$$
\Gamma=\frac{C_{A w}}{C_{A f}}-1
$$




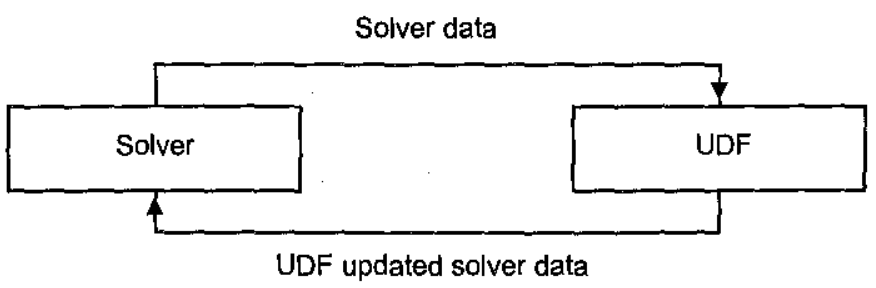

Figure 3 Access of solver data by UDF for a single iteration loop

Average concentration polarization factor, $\vec{\Gamma}$ will be evaluated by numerical integration over the membrane channel length.

$$
\bar{\Gamma}=\frac{1}{l} \times \int_{0}^{l} \Gamma(x) d x
$$

Mass transfer coefficient, $k$ will also be determined according to this relation:

$$
k=\frac{D_{A B}}{\delta}
$$

Average mass transfer coefficient, $\bar{k}$ will be evaluated by numerical integration over the membrane channel length.

$$
\bar{k}=\frac{1}{l} \times \int_{0}^{l} k(x) d x
$$

Wall shear stress, $\tau_{w}$ will be evaluated from the simulation data which can be represented by:

$$
\tau_{w}=\mu \frac{\partial u}{\partial y}
$$

\subsection{RESULTS AND DISCUSSION}

\subsection{Effect of Reynolds Number Towards Concentration Factor}

The flow in the membrane channel tends to approach fully developed profile along the membrane channel since fully developed region has been defined in the channel outflow. The velocity will decrease rapidly near the wall entrance region and the rate of decline will reduce when it is approaching the fully developed region. For the reason, concentration build-up will increase rapidly near the wall entrance region due to the rapid decrease in velocity. When the fluid flow is approaching the fully developed region, the velocity reduction rate is constant. The moderate reduction of velocity has constrained the growth rate of concentration polarization layer on the membrane interface. This phenomenon has contributed to the evolution trend as depicted in Figure 4 for the dimensionless concentration factor $\left(C_{A w} / C_{A f}\right)$ versus the dimensionless channel length $(x / h)$. Higher Reynolds 


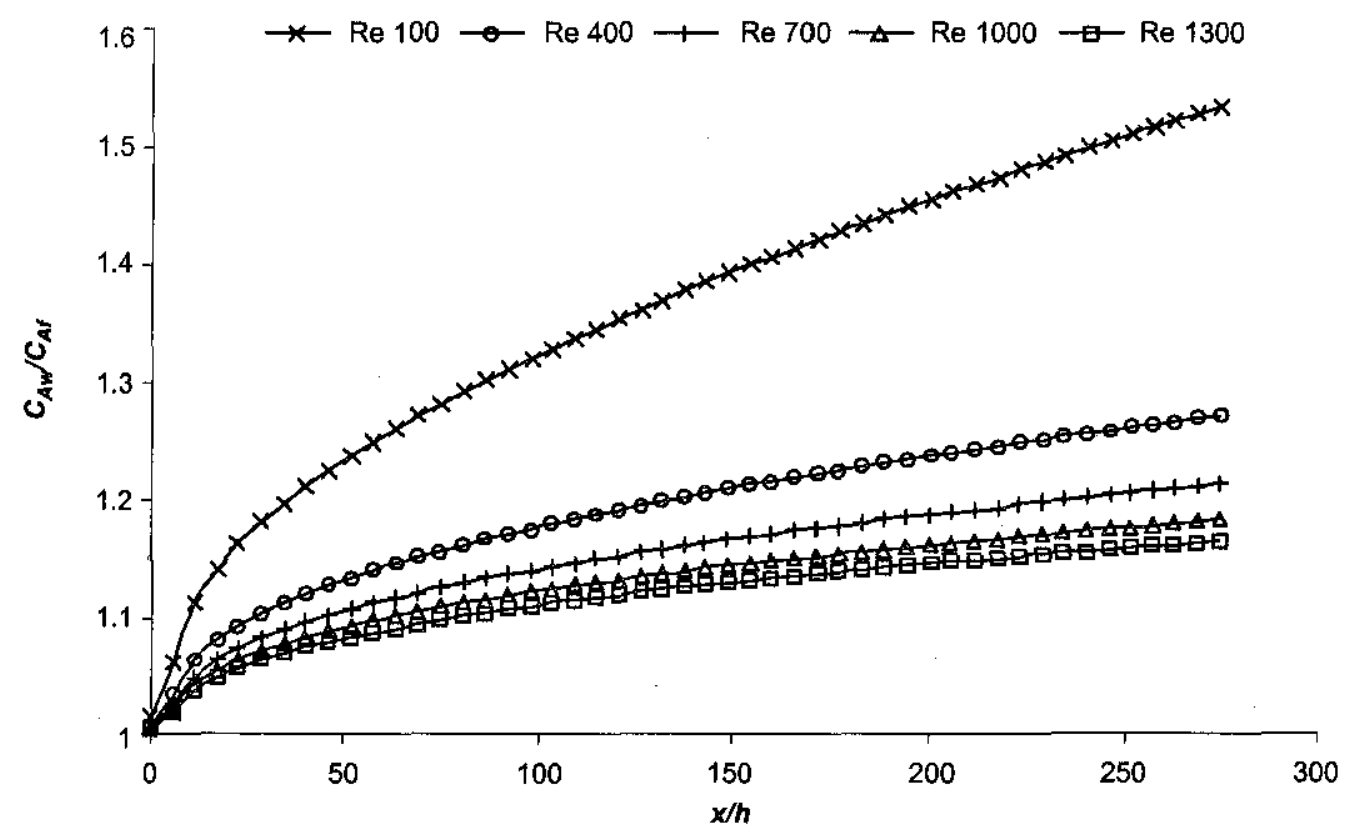

Figure 4 Evolution of membrane wall concentration factor under different feed Reynolds number ( $\Delta P$ $=1.0 \mathrm{MPa})$

number will responsible to the generation of higher cleaning effect on the concentration polarization layer and directly deters its formation. Thus, Figure 4 shows that higher feed Reynolds tends to produce less membrane wall concentration factor than lower feed Reynolds number.

\subsection{Effect of Reynolds Number Towards Wall Shear Stresses}

Wall shear stress plays the key role for generating scouring effect on the membrane interface and reduces the potential of concentration polarization formation. Based on Figure 5, wall shear stress, $\tau_{w}$ is decreasing rapidly near the wall entrance region and exhibits a nearly constant trend when it is approaching fully developed region. Rapid decreasing of wall shear stress near the wall entrance region promotes the formation of membrane wall concentration. Higher feed Reynolds number tends to produce higher wall shear stress and minimize the formation of concentration polarization layer as depicted in Figure 5.

\subsection{Effect of Reynolds Numbers Towards Mass Transfer Coefficient}

Mass transfer coefficient, $k$ which is a function of Schmidt $\left(S c=\mu / \rho D_{A B}\right)$ and Reynolds number, tend to decrease with the reduction of Reynolds number by assuming constant Schmidt number. Figure 6 demonstrates the evolution of mass transfer coefficient under different feed Reynolds number $(\mathrm{Re})$ in the narrow membrane channel. The rapid decline in velocity near the wall entrance region has causes the $k$ value to reduce drastically at lower dimensionless channel length $(x / h)$, as depicted in the Figure 6 . After this region, $k$ value is reducing gradually along the narrow membrane channel 


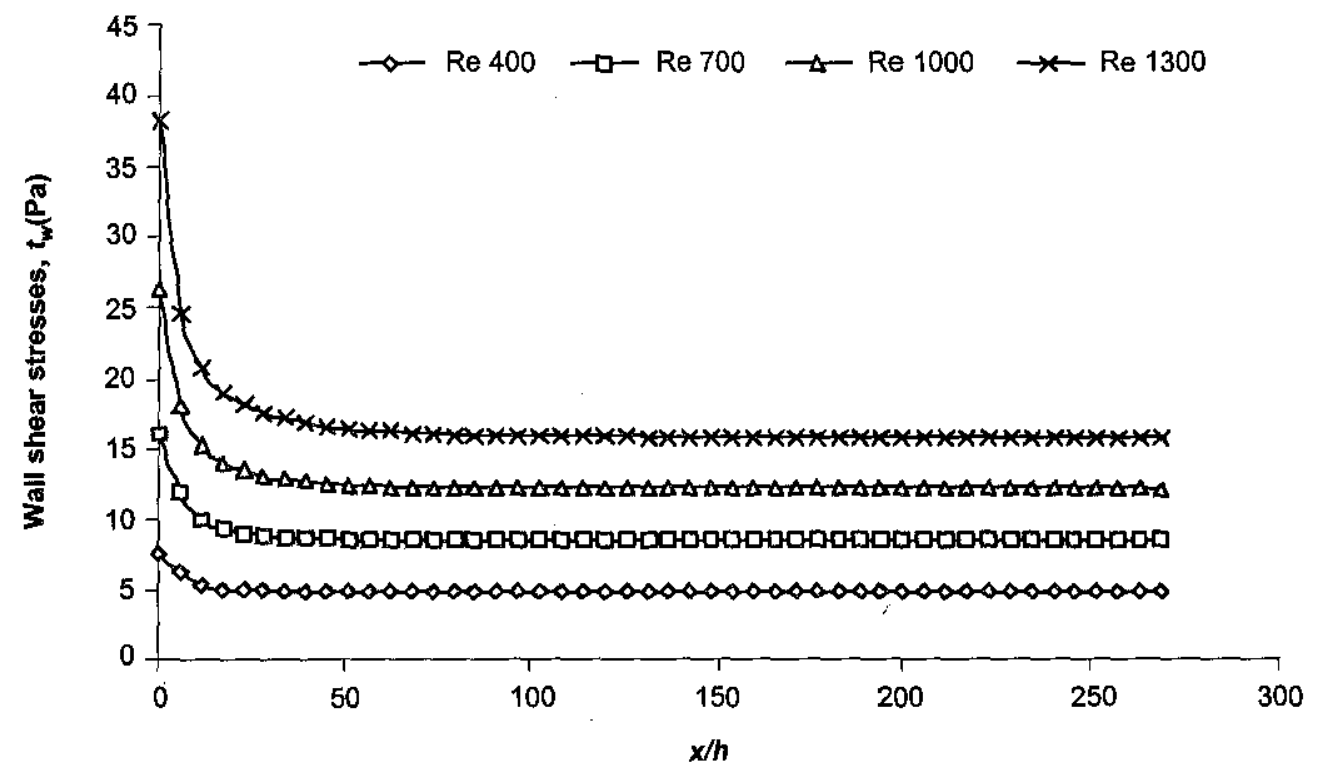

Figure 5 Evolution of wall shear stresses along the membrane channel length for different types of feed Reynolds number $(\Delta P=1.0 \mathrm{MPa})$

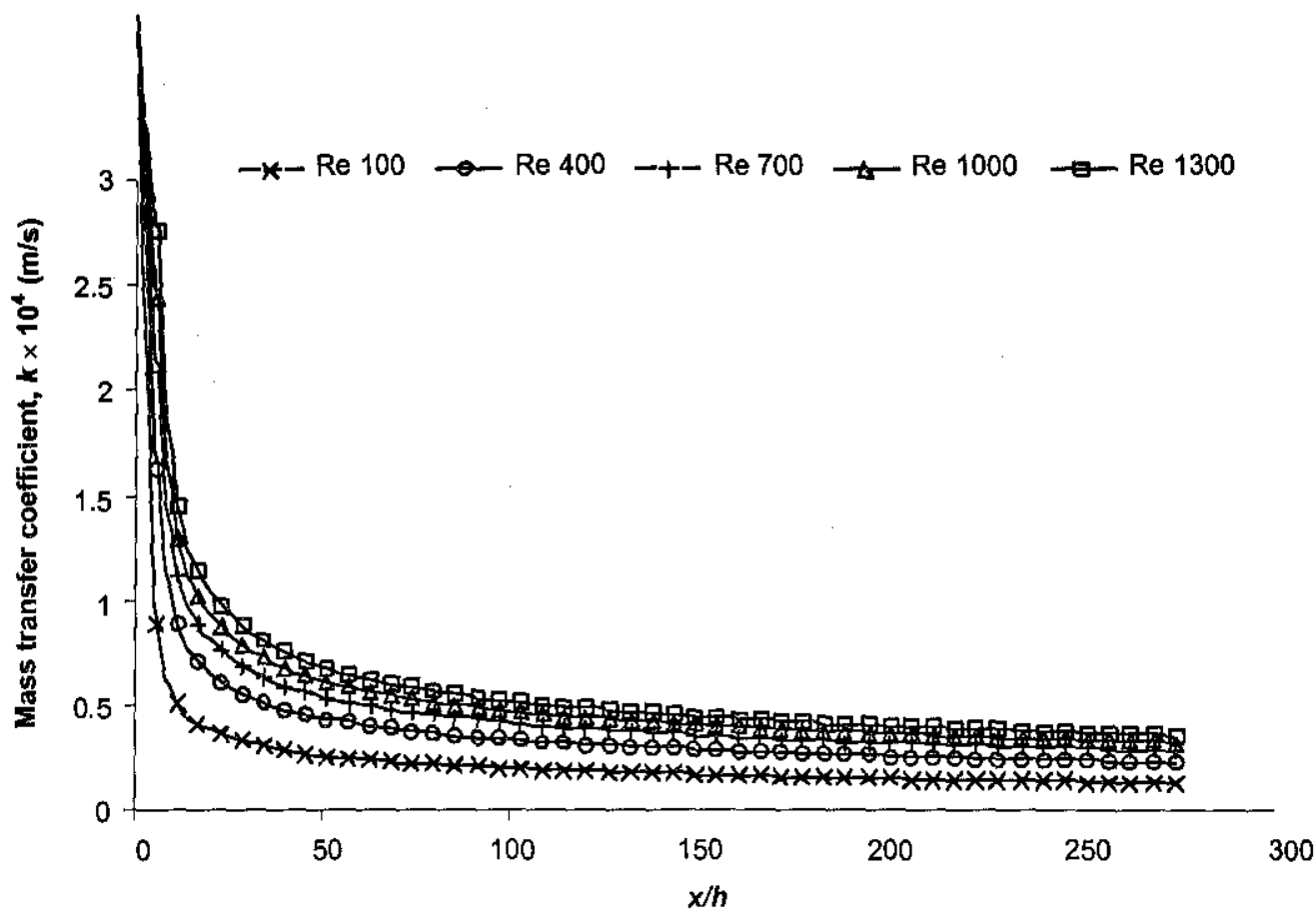

Figure 6 Evolution of mass transfer coefficient under different feed Reynolds number $(\Delta P=1.0 \mathrm{MPa})$ 
Table 2 Average value for membrane wall concentration factor, $\overline{\left(C_{A w} / C_{A f}\right)}$ and mass transfer coefficient, $\bar{k}$ for feed concentration $\mathrm{C}_{A f}=0.2 \mathrm{~kg} / \mathrm{m}^{3}$

\begin{tabular}{|c|c|c|}
\hline Feed Reynolds Number & $\overline{\left(C_{A w} / C_{A f}\right)}$ & $\bar{k} \times 10^{5}(\mathrm{~m} / \mathrm{s})$ \\
\hline \multicolumn{3}{|c|}{$\Delta P=1 M P a, C_{A P}=5.4 \times 10^{-3} \mathrm{~kg} / \mathrm{m}^{3}$} \\
\hline 100 & 1.364 & 2.37 \\
\hline 400 & 1.193 & 4.17 \\
\hline 700 & 1.152 & 5.23 \\
\hline 1000 & 1.132 & 6.05 \\
\hline 1300 & 1.119 & 6.73 \\
\hline \multicolumn{3}{|c|}{$\Delta P=2 M P a, C_{A P}=3.7 \times 10^{-5} \mathrm{~kg} / \mathrm{m}^{3}$} \\
\hline 100 & 2.191 & 2.37 \\
\hline 400 & 1.508 & 4.17 \\
\hline 700 & 1.383 & 5.23 \\
\hline 1000 & 1.322 & 6.05 \\
\hline 1300 & 1.285 & 6.73 \\
\hline \multicolumn{3}{|c|}{$\Delta P=3 \mathrm{MPa}, C_{A P}=2.9 \times 10^{-5} \mathrm{~kg} / \mathrm{m}^{3}$} \\
\hline 100 & 4.723 & 2.37 \\
\hline 400 & 2.046 & 4.17 \\
\hline 700 & 1.729 & 5.23 \\
\hline 1000 & 1.593 & 6.05 \\
\hline 1300 & 1.514 & 6.73 \\
\hline
\end{tabular}

due to the constant reduction of velocity. Besides, magnitude increment in feed Reynolds number exhibits higher $k$ value. The variation of feed Reynolds number from 100 to 1300 will yield $k$ values in ascending manner. The detail results are tabulated in Table 2.

\subsection{Effect of Transmembrane Pressure Towards Concentration Factor}

By setting feed Reynolds number and concentration constant, higher transmembrane pressure will demonstrate an increment in membrane wall concentration. This phenomenon is shown in Figure 7. The increment in transmembrane pressure will generate higher permeation flux which subsequently promotes the development of membrane wall concentration. This phenomenon has been found to be in accordance with the published literature [3]. Table 2 shows the variation of feed Reynolds number and transmembrane pressure towards the development of membrane wall concentration factor. According to Table 2 , the average concentration polarization factor, $\overline{\left(C_{A w} / C_{A f}\right)}$ is found to decrease from 1.364 to 1.119 with the increase of feed Reynolds number from 100 to 1300 under $1 \mathrm{MPa}$ transmembrane pressure. Similar trend can be observed for transmembrane pressure $2 \mathrm{MPa}$ and 3 MPa.

\subsection{Concentration Factors for Different Location in the Membrane Channel}

Figure 8 shows the $\mathrm{NaCl}$ concentration factor, $\left(\mathrm{C}_{A w} / \mathrm{C}_{A f}\right)$ for the distance of $1 \mathrm{~cm}$ and $20 \mathrm{~cm}$ from the channel entrance. The $\mathrm{NaCl}$ concentration factor demonstrates an increment along the narrow 


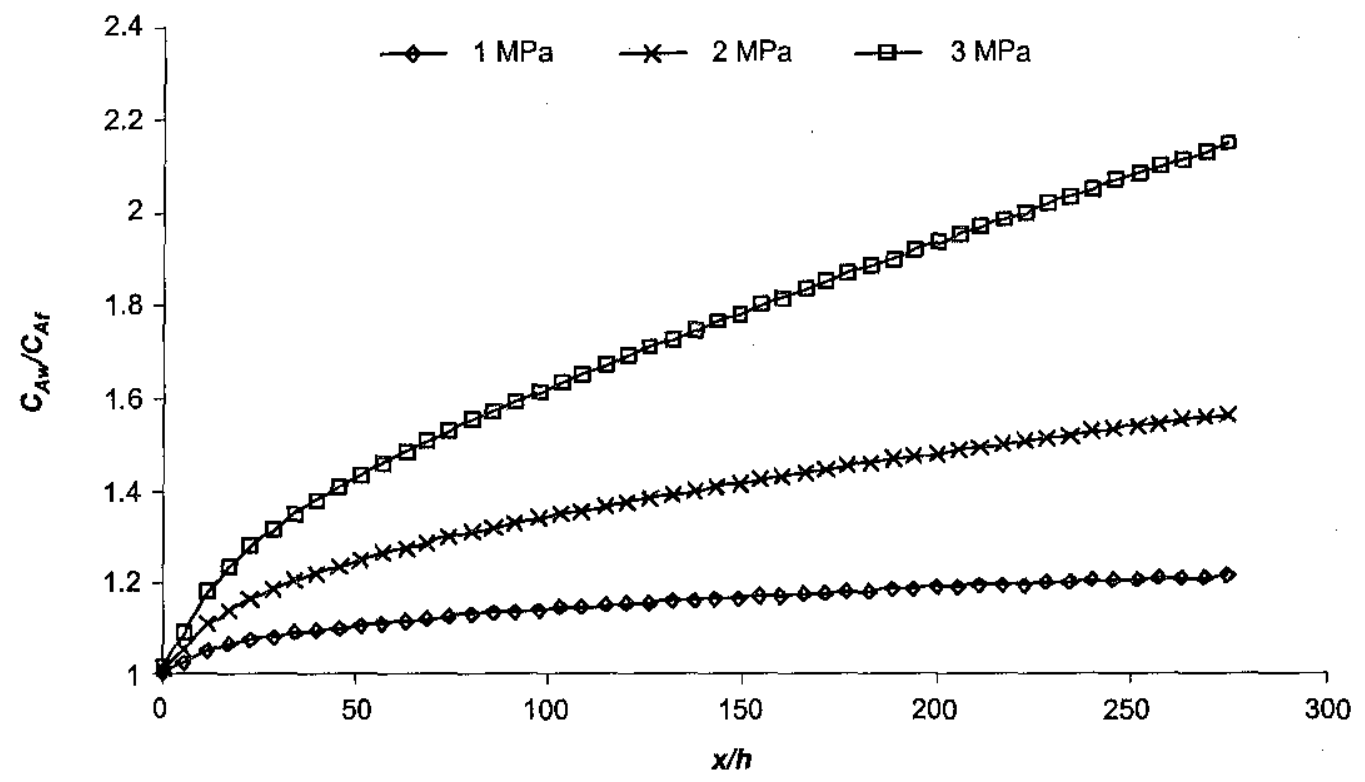

Figure 7 Evolution of membrane wall concentration factor under different transmembrane pressure $(\operatorname{Re}=700)$

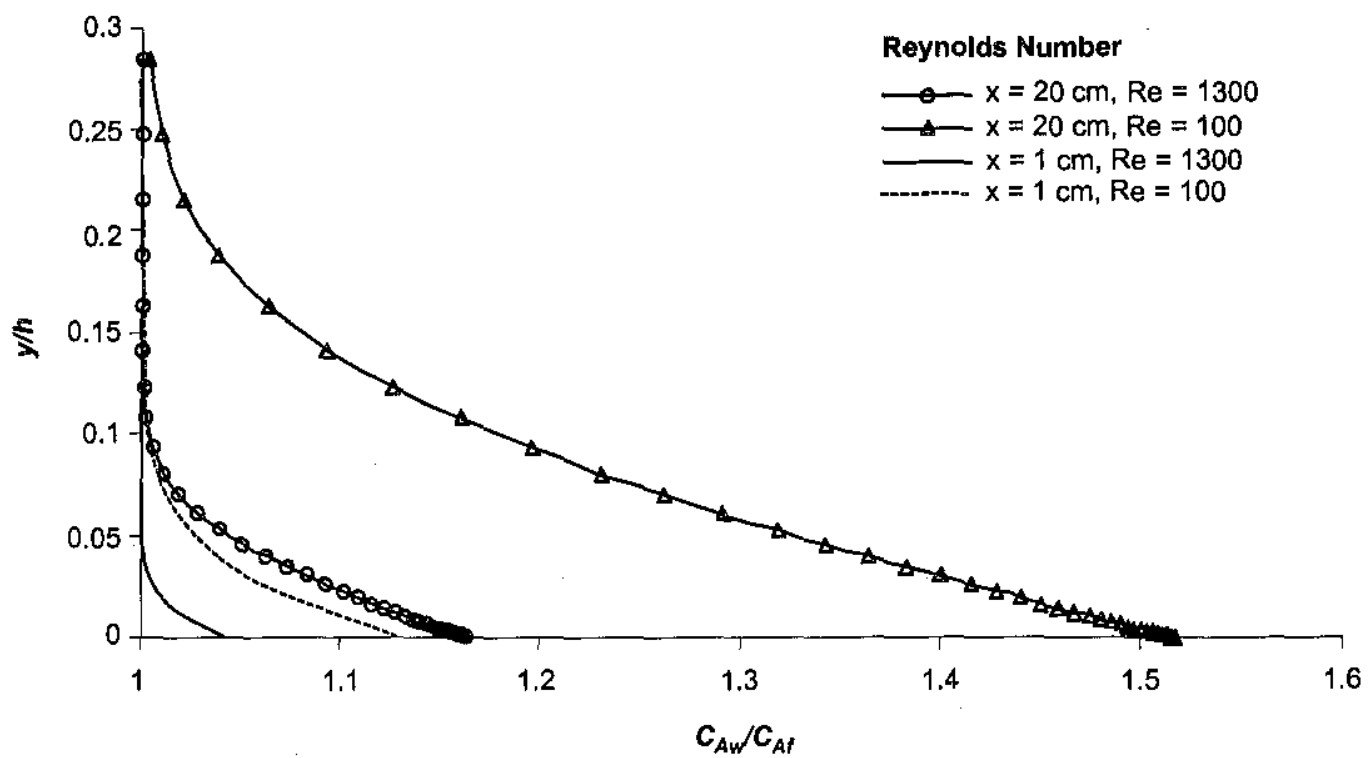

Figure 8 Effect of channel height on membrane wall concentration factor under feed Reynolds number 100 and 1300 in the narrow membrane channel at $x=1 \mathrm{~cm}$ and $20 \mathrm{~cm}$. Inlet feed concentration, $\mathrm{C}_{A f}=0.2 \mathrm{~kg} / \mathrm{m}^{3} \& \Delta P=1.0 \mathrm{MPa}$ 
membrane channel from 1 to $20 \mathrm{~cm}$, as shown in Figure 8. The higher concentration factor for lower dimensionless channel height $(y / h)$ indicates that concentration polarization profile is being built up at the laminar region adjacent to the membrane. Higher feed Reynolds number $(1300)$ will generate less concentration build-up on the membrane surface compared with the lower feed Reynolds number (100). The difference of concentration build-up phenomena for two extreme feed Reynolds number can be observed with the increment of horizontal distance from the channel entrance $x=1.0 \mathrm{~cm}$ to $x=20 \mathrm{~cm}$. This trend is found to be in good agreement with the published data from literature [3].

\subsection{Comparison Between Simulated and the Published Literature Data}

Figure 9 shows the comparison between simulated data and the published literature data [3] for the $\Gamma\left(\left(C_{A z u} / C_{A f}\right)-1\right)$ versus dimensionless channel length $(x / h)$. Obviously, the simulated data demonstrate similar evolution trend with the literature data. As mentioned in the theory section, permeation flux has been considered in the film theory but ignored hydrodynamically (assuming wall boundary condition for membrane) due to the limitation of the simulator. The existence of permeation flux hydrodynamically is plausible to reduce the formation of the concentration polarization profile on the membrane surface. This has been proven by De \& Bhattacharya [22]. With the absence of permeation flux hydrodynamically, the simulated data is postulated to be larger in terms of magnitude if compared with the literature data [3]. For lower transmembrane pressure simulation, the effect of the permeation flux to the hydrodynamics is small due to the smaller permeation rate. Hence, the simulated data is predicted to be in good agreement with the literature data. However, the simulated datas is found to be slightly lower if compared with the literature data. This might be due to the variation of calculation method which applies in the formulation of both data respectively. For higher transmembrane pressure data $(3 \mathrm{MPa})$, simulated data tend to exceed the values reported in literature. Under this circumstance, the effect of the permeation flux towards the fluid's hydrodynamics is significant due to the higher permeation rate. The absence of this permeation flux hydrodynamically in the membrane surface has promoted the formation of higher concentration polarization profile for the simulated data at higher permeation flux as depicted in Figure 9.

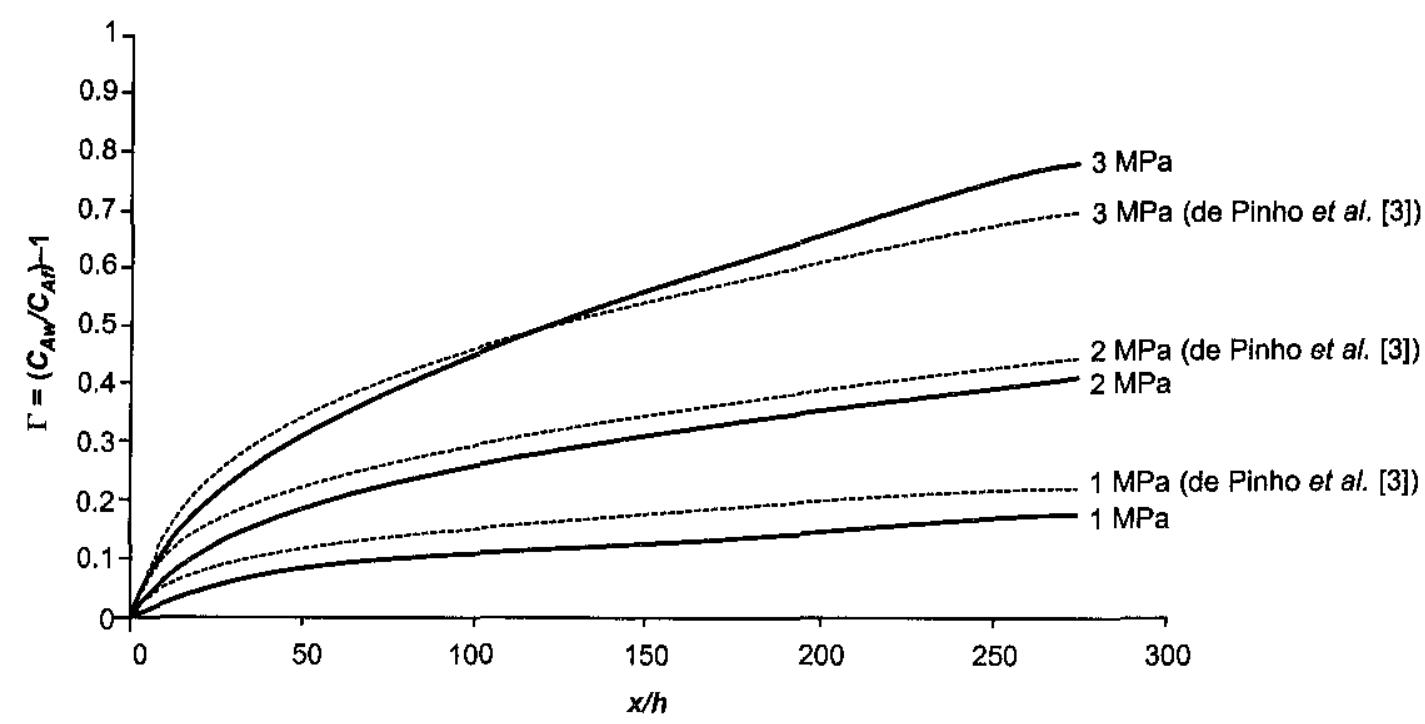

Figure 9 Data comparison between simulated data and published literature data [3] 


\subsection{CONCLUSION}

The employment of CFD modified boundary condition simulation is capable to predict the concentration polarization profile that developed in the membrane interface. This has been proven from the simulated data which exhibit a well accordant trend with the published data from literature. The incorporation of permeation properties in the modified boundary condition had predicted the membrane wall concentration profile, membrane wall shear stress and mass transfer coefficient in the narrow membrane channel. Based on current CFD simulation, the increment in feed Reynolds number contributes to the raise in mass transfer coefficient and suppresses the formation of membrane wall concentration. Higher feed Reynolds number also generates higher wall stress which deters the formation of membrane wall concentration.

\section{ACKNOWLEDGEMENTS}

This work was funded by Grant IRPA EA by Ministry of Science, Technology and Innovation Malaysia. The authors would like to acknowledge our appreciation to NSF MOSTI for providing financial support to Mr. K. K. Lau. The authors would also like to thank the School of Mechanical Engineering, Universiti Sains Malaysia, for providing computing software FLUENT v6.0.12.

\section{NOMENCLATURE}

$C_{A}$ solute concentration ( $\mathrm{kg}$ solute $/ \mathrm{m}^{3}$ solution)

$D_{A B}$ binary mass coefficient $\left(\mathrm{m}^{2} / \mathrm{s}\right)$

$h$ channel height

$J_{v} \quad$ permeate volume flux $(\mathrm{m} / \mathrm{s})$

$k$ mass transfer coefficient $(\mathrm{m} / \mathrm{s})$

$\bar{k} \quad$ average mass transfer coefficient $(\mathrm{m} / \mathrm{s})$

$l$ narrow membrane channel length $(\mathrm{m})$

$m_{A}$ mass fraction

$R e \quad$ feed Reynolds number $\left(R e=\rho u_{0} h / \mu\right)$

Sc Schmidt number $\left(S c=\mu / \rho D_{A B}\right)$

$u \quad$ velocity in $\mathrm{x}$-direction $(\mathrm{m} / \mathrm{s})$

$v \quad$ velocity in $\mathrm{y}$-direction $(\mathrm{m} / \mathrm{s})$

$x \quad \mathrm{x}$ coordinate

$y \quad y$ coordinate

\section{Greeks letters}
$\tau_{w} \quad$ wall shear stress $(\mathrm{Pa})$
$\rho$ density $\left(\mathrm{kg} / \mathrm{m}^{3}\right)$
$\mu \quad$ viscosity $(\mathrm{kg} / \mathrm{m}, \mathrm{s})$ 
$\Delta P \quad$ transmembrane pressure $(\mathrm{Pa})$

$\delta$. concentration polarization thickness (m) $\left(\delta=\ln \left(\frac{m_{A z v}-m_{A p}}{m_{A 0}-m_{A p}}\right) \times \frac{D_{A B}}{J_{v}}\right)$

\author{
Subscript \\ $f \quad$ feed solution \\ $p \quad$ permeate side \\ w solution adjacent to the wall
}

\title{
REFERENCES
}

[1] Geraldes, V., V. Semiao, and M. N. de Pinho. 2000. Numerical Modeling of Mass Transfer in Slits with Semi-permeable Membrane Walls. Eng. Comput. 17: 192.

[2] Geraldes, V., V. Semiao, and M. N. de Pinho. 2001. Flow and Mass Transfer Modelling of Nanofiltration. J. Membr. Sci. 191: 109-128.

[3] de Pinho, M. N., V. Semiao, and V. Geraldes. 2002. Integrated Modeling of Transport Processes in Fluid/nanofiltration Membrane Systems. J. Membr. Sci. 206: 189-200

[4] Miranda, J. M., and J. B. L. M. Campos. 2001. An Improved Numerical Scheme to Study Mass Transfer Over a Separation Membrane. J. Membr. Sci. 188: 49-59

[5] Geraldes, V., V. Semiao, and M. N. de Pinho. 2002. The Effect of the Ladder-type Spacers Configuration in NF Spiral-wound Modules on the Concentration Boundary Layers Disruption. Desalination. 146: 187-194.

[6] Geraldes, V., V. Semiao, and M. N. de Pinho. 2003. Hydrodynamics and Concentration Polarization in RO/NF Spiral Wound Modules with Ladder Type Spacer. Desalination. 157: $395-402$

[7] Geraldes, V., V. Semiao, and M. N. de Pinho. 2004. Concentration Polarisation and Flow Structure Within Nanofiltration Spiral-wound Modules with Ladder-type Spacers. Computers and Structures. 82: 1561-1568

[8] Cao, Z., D. E. Wiley, and A. G. Fane. 2001. CFD Simulation of Net-type Turbulence Promoters in a Narrow Channel. J. Membr. Sci. 185:157-176.

[9] Koutsou, C. P, S. G. Yiantsios, and A. J. Karabelas. 2004. Numerical Simulation of the Flow in a Plane-channel Containing a Periodic Array of Cylindrical Turbulence Promoters. J. Membr. Sci. 231: 81-90.

[10] Schwinge, J., P. R. Neal, D. E. Wiley, D. F. Fletcher, and A. G. Fane. 2004. Spiral Wound Modules and Spacers Review and Analysis. J. Membr. Sci. 242:129-153.

[11] Schwinge, J., D. E. Wiley, and D. F. Fletcher. 2002. Simulation of Flow Around Spacer Filaments Between Channels Walls. Part I. Hydrodynamics. Ind. Eng. Chem. Res. 41: 2977-2987.

[12] Schwinge, J., D. E. Wiley, and D. F. Fletcher. 2002. Simulation of Flow Around Spacer Filaments Between Channels Walls. Part II. Mass transfer. Ind. Eng. Chem. Res. 41: 4879-4888.

[13] Schwinge, J., D. E. Wiley, and D. F. Fletcher. 2003. Simulation of Flow Around Spacer Filaments Between Channels Walls. Unsteady flows. Ind. Eng. Chem. Res. 42: 4962-4977.

[14] Schwinge, J., D. E. Wiley, and D. F. Fletcher. 2002. A CFD Study of Unsteady Flow in Narrow Spacer-filled Channels for Spiral Wound Membrane Modules. Desalination. 146: 195-201. 
[15] Li, F., G. W. Meindersma, A. B. de Haan, and T. Reith. 2002. Optimisation of Non-woven Spacers by CFD and Validation by Experiments. Desalination. 146: 209.

[16] Li, F., G. W. Meindersma, A. B. de Haan, and T. Reith. 2002. Optimisation of Commercial Net Spacers in Spiral Wound Membrane Modules. J. Membr. Sci. 208: 289-302.

[17] Li, F., G. W. Meindersma, A. B. de Haan, and T. Reith. 2004. Experimental Validation of CFD Mass Transfer Simulations in Flat Channels with Non-oven Net Spacers. J. Membr. Sci. 232: $19-30$

[18] Wiley, D. E., and D. F. Fletcher. 2003. Techniques for Computational Fluid Dynamics Modeling of Flow in Membrane Channels. J. Membr. Sci. 211: 127-137.

[19] Wiley, D. E., and D. F. Fletcher. Computational Fluid Dynamics Modeling of Flow and Permeation for Pressure-driven Membrane Processes. Desalination. 145: 183-186

[20] Perry, R. H. 1997. Perry's Chemical Engineer's Handbook. Seventh Edition. McGraw-Hill.

[21] Geankoplis, C. J. 1995. Transport Processes and Unit Operations. Third Editions. Prentice Hall International Inc.

[22] De. S., and P. K. Bhattacharya. 1997. Prediction of Mass-transfer Coefficient with Suction in the Applications of Reverse Osmosis and Ultrafiltration. J. Membr. Sci. 128:119-131. 